\title{
OPTIMAL COORDINATION POLICY FOR SUPPLY CHAIN SYSTEM UNDER IMPERFECT QUALITY CONSIDERATION
}

Tien-Y Lin

Department of Marketing and Distribution, Overseas Chinese University, Taichung, Taiwan, R.O.C, admtyl@ocu.edu.tw

Din-Horng Yeh

Department of Business Administration, National Chung-Cheng University, Chia-Yi, Taiwan, R.O.C

Follow this and additional works at: https://jmstt.ntou.edu.tw/journal

Part of the Business Commons

\section{Recommended Citation}

Lin, Tien-Y and Yeh, Din-Horng (2010) "OPTIMAL COORDINATION POLICY FOR SUPPLY CHAIN SYSTEM UNDER IMPERFECT QUALITY CONSIDERATION," Journal of Marine Science and Technology. Vol. 18: Iss. 3, Article 17. DOI: $10.51400 / 2709-6998.1893$

Available at: https://jmstt.ntou.edu.tw/journal/vol18/iss3/17

This Research Article is brought to you for free and open access by Journal of Marine Science and Technology. It has been accepted for inclusion in Journal of Marine Science and Technology by an authorized editor of Journal of Marine Science and Technology. 
OPTIMAL COORDINATION POLICY FOR SUPPLY CHAIN SYSTEM UNDER IMPERFECT QUALITY CONSIDERATION

Acknowledgements

The authors are grateful to the anonymous referees for their very valuable and helpful suggestions on an earlier version of the paper 


\title{
OPTIMAL COORDINATION POLICY FOR SUPPLY CHAIN SYSTEM UNDER IMPERFECT QUALITY CONSIDERATION
}

\author{
Tien-Yu Lin* and Din-Horng Yeh**
}

Key words: supply chain coordination, ordering lead time, pricing policy, imperfect quality.

\begin{abstract}
We considered a simple single-vendor, single-buyer supply chain system, in which the buyer's ordering lead time is affected by purchasing price discounts which in turn are affected by the vendor's pricing policy. Both parties in the supply chain system have conflicting goals: the buyer wants to minimize his total cost while the vendor aims to maximize his total profit. In order to guarantee the mutual interest of both parties, we have developed a mathematical model to illustrate how the best supply chain system benefit can be achieved through coordinating the buyer's ordering lead time and the vendor's pricing policy. For practical purposes, risk costs and the effect of imperfect quality are also included in the model. A numerical example and related sensitivity analysis are given to show the effectiveness of the proposed model.
\end{abstract}

\section{INTRODUCTION}

The issue of coordination in supply chain management (SCM) has received considerable attention from academic researchers and practitioners. Traditionally, both vendors and buyers in the supply chain system make decisions in search of their individual benefits. However, many researchers (e.g. [32, $35,41,46]$, etc.) have pointed out that coordination between both parties is important in order to gain competitive advantages through cost reduction. The importance of coordination is further increased because vendors and buyers frequently implement the just-in-time (JIT) concept in their own systems. A recent study pointed out that coordination is crucial to successful JIT implementation for both parties [17]. A key technique in successful SCM is JIT application to multiple deliv-

Paper submitted 09/19/08; revised 06/04/09; 07/20/09; accepted 09/03/09. Author for correspondence: Tien-Yu Lin (e-mail: admtyl@ocu.edu.tw).

*Department of Marketing and Distribution, Overseas Chinese University, Taichung, Taiwan, R.O.C.

**Department of Business Administration, National Chung-Cheng University, Chia-Yi, Taiwan, R.O.C. eries. Chung and Wee [7] showed that increases in quality, productivity, and efficiency can be achieved through JIT delivery agreements. A recent study showed that if a long-term relationship has been established, both parties in the supply chain system can achieve further improved benefits through cooperation and information sharing [5]. Rau and OuYang [36] presented a new integrated production-inventory policy that showed that the performance of integrated consideration is better than the performance of any independent decision from either the buyer or the vendor.

Goyal [10] was among the first researchers focusing on the joint economic lot size (JELS) problem in the supply chain system, in which an integrated inventory model was developed assuming the vendor's production rate was infinite. Banerjee [2] generalized Goyal's model so that the vendor produced to the buyer's order on a lot-for-lot shipment policy. Later, Goyal [11] relaxed the lot-for-lot shipment assumption and proposed a more general JELS model that provided a lower-joint total relevant cost, in which he suggested that the vendor's economic production quantity (EPQ) should be an integer multiple of the buyer's purchase quantity. Landeros and Lyth [20] generalized these models by incorporating the fixed shipment cost associated with each delivery to the buyer. Recently, Goyal [12] and Hill [14] proposed different shipment policies and suggested that each shipment size should be determined by the first shipment size and rate of production/demand. As shown by Viswanathan [43], neither a policy with equal-sized sub-batches nor a policy with unequal-sized sub-batches dominated the other. Ertogral et al. [8] further analyzed the vendor-buyer lot-sizing problem under equalsize shipment policy, in which they incorporated transportation costs explicitly into the model and developed optimal solution procedures for solving the integrated models. More recently, Ben-Daya et al. [3] presented a comprehensive and up-to-date review of the joint economic lot sizing problem and also provided some extensions of this important problem. To simplify analysis, many researchers discuss the supply chain system with a single-vendor and single-buyer.

A globally optimal batching and shipment policy for a two-echelon supply chain with single-vendor and single-buyer was established by Hill [15], in which he pointed out that the successive shipment size of the first $m$ shipments using a fixed 
factor. Hoque and Goyal [16] suggested an optimal procedure for a single-vendor and single-buyer production-inventory problem with equal-sized and unequal-sized shipments, in which a transportation equipment capacity constraint was included. Pan and Yang [29] proposed an integrated inventory model with controllable lead time, and later Chang et al. [5] extended their model to an integrated cooperative inventory model with controllable lead time and ordering cost reduction. Further, Huang [17] developed an optimal policy for a single-vendor and single-buyer integrated production-inventory problem with process unreliability consideration. More recently, Chen and Kang [6] developed integrated vendor-buyer cooperative inventory models with the permissible delay in payments to determine the optimal replenishment time interval and replenishment frequency.

In practice it quite often occurs that inventory management is affected by imperfect product quality. Porteus [34] integrated the effect of imperfect items into the basic EOQ model, in which he used the simple model to illustrate the relationship between quality and lot size. Rosenblatt and Lee [38] assumed that defective items could be reworked instantly at a cost and they found that the presence of defective products motivated smaller lot sizes. Later, Schwaller [42] assumed that defective items were present in incoming lots and the inspection costs should be incurred in finding and removing such items. An EOQ-based model with demand-dependent unit production cost and imperfect production processes was proposed by Gerchak [9], in which he formulated the inventory decision problem as a geometric program that was solved to obtain optimal solutions. Salameh and Jaber [40] also developed an EOQ-based model for items received with imperfect quality, in which they assumed that the defective quantities could be sold as a single batch by the end of $100 \%$ screening process. They found that the economic lot size increased as the average percentage of flawed quality items increased. Goyal and Cardenas-Baeeon [13] proposed a simple method for determining the EPQ for an item with imperfect quality. Recently, Huang [17] developed a model to determine an optimal integrated vendor-buyer inventory policy for imperfect items in JIT environment. Papachristos and Konstantaras [31] focused on the issue of no shortages in EOQ-based models with proportional flawed quality, in which the proportion of the imperfects was assumed to be a random variable. More recently, Wee et al. [45] developed an optimal inventory model for items with imperfect quality and shortage backordering in which the optimum operating inventory strategy was obtained by trading off the total revenues per unit time. Furthermore, Maddah and Jaber [23] developed an EOQ-based model with unreliable supply, characterized by a random fraction of imperfect quality items and a screening process. They rectified a flaw developed by Salameh and Jaber [40].

According to Chang et al. [5], controllable lead time and ordering cost reduction were keys to business success. Liao and Shyu [22] were among the first to develop a probabilistic inventory model in which lead time was a unique variable and order quantity was predetermined. Ben-Daya and Raouf [4] integrated the lead time and ordering quantity as decision variables in which shortages were not permitted. Recently, Ouyang et al. [27] investigated the impact of investing in quality improvement and lead time reduction on the integrated vendor-buyer inventory model with partial backorders. Chang et al. [5] assumed buyer's lead time can be shortened at an extra crash cost that depended on the lead time and the ordering lot size. The buyer's ordering cost could be reduced through further investment. More recently, Zhao et al. [47] developed an analytical model to quantify the cost savings of an early order commitment in a two-level supply chain where demand was serially correlated, and they pointed out that the supply chain would experience greater savings from early order commitment.

Recent operations management literature began to focus on developing integrated models that can simultaneously optimize the relevant inventory (operations) and pricing (marketing) decisions [39]. A literature review on pricing and ordering policies for manufacturer-retailer supply chains was made by Khouja [18]. In the meantime, Petruzzi and Dada [33] also made a review with extensions on pricing and the newsvendor problem. Mantrala and Raman [24] further investigated the effect of the retailer's optimal ordering quantity decisions under demand uncertainty. Lau and Lau [21] developed a joint pricing-inventory model and they found that different demand functions could lead to very different results in a multi-echelon system. Later, Viswanathan and Wang [44] developed a simple vendor-retailer supply chain model in which the retailer faces a price-sensitive deterministic demand. Ray et al. [37] further introduced an integrated marketinginventory model for two pricing policies in which they considered price as a decision variable using mark-up pricing. More recently, Bakal et al. [1] presented two inventory models with price-sensitive demand and they investigated two different pricing strategies. Pan et al. [30] further constructed a two-period model to discuss pricing and ordering problems for a dominant retailer under a two-echelon supply chain.

Although supply chain system coordination has received considerable attention, the effect of ordering lead time is neglected by most researchers. In practice, it is often the case that the vendor benefits if the buyer places its orders earlier. The reason is that if the buyer's ordering lead time is long, the vendor may then have the opportunity to make a more efficient production plan. This means that the vendor's unit production cost can be decreased. Consequently, the vendor's total profit will be increased because of the reduction of its production cost. On the other hand, to motivate the buyer to place orders earlier, the vendor is willing to offer price discounts in which the unit selling price is allowed to be decreased for long ordering lead time and/or large order quantity. As a consequence, the buyer's total cost will be decreased because of the decrease in unit purchasing price offered by the vendor. According to the above discussion and based on the work of Huang [17], this paper developed a coordination model that incorporates 
the vendor's pricing policy, the buyer's ordering lead time and imperfect product quality. In this model we investigated the effects of both the vendor's pricing policy and the buyer's ordering lead time on the supply chain system benefit. We showed that both parties can benefit and the supply chain system benefit can be optimized through coordination.

\section{NOTATIONS AND ASSUMPTIONS}

We adopted the notations and assumptions used by Huang [17] to develop the proposed coordination model as follows.

\section{Notations: \\ D known annual demand \\ $F \quad$ transportation cost per shipment \\ I buyer's inventory holding cost as percentage of its unit purchasing cost \\ $M \quad$ production rate, in which $M>D$ \\ $S_{V} \quad$ setup cost per production run for the vendor \\ $S_{B} \quad$ ordering cost for the buyer \\ $h_{V} \quad$ unit stock-holding cost per item per year for the vendor \\ $h_{B} \quad$ unit stock-holding cost per item per year for the buyer \\ $P_{0} \quad$ unit purchasing cost for the buyer with zero or- dering lead time \\ $C_{0} \quad$ unit production cost for the vendor with zero ordering lead time \\ $d \quad$ unit screening cost \\ $x \quad$ screening rate \\ $r \quad$ the coefficient of inflection for vendor \\ $v \quad$ the vendor's unit warranty cost of defective items \\ $z \quad$ the coefficient of inflection for buyer \\ $\alpha \quad$ the parameter of production cost reduction rate \\ $\beta \quad$ the parameter of price discount rate \\ $Y \quad$ percentage of defective items, a random variable \\ $f(y) \quad$ probability density function of $Y$ \\ $P(T) \quad$ unit purchasing cost for the buyer if ordering lead time is $T$ \\ $C(T) \quad$ unit production cost for the vendor if ordering lead time is $T$ \\ $R_{B}(T) \quad$ unit risk cost for buyer if ordering lead time is $T$ \\ $R_{V}(T) \quad$ unit risk cost for vendor if ordering lead time is $T$}

Decision variables:

$Q \quad$ the size of each shipment from the vendor to the buyer

$T \quad$ ordering lead time for the buyer

$n \quad$ the total number of shipments per lot from the vendor to the buyer

$C_{B} \quad$ the total cost for the buyer

$\pi_{V} \quad$ the total profit for the buyer

$E\left[T C_{B}\right]$ the expected total cost for the buyer

$E\left[T C_{B}^{\text {old }}\right]$ the buyer's expected total cost without purchas- ing discount

$E\left[T C_{B}^{n e w}\right]$

the buyer's expected total cost with purchasing discount

$E\left[\pi_{V}\right] \quad$ the expected total profit for the vendor

$\Delta \pi_{V} \quad$ net increase of profit for the vendor, in which $\Delta \pi_{V}=E\left[\pi_{V}^{\text {new }}\right]-E\left[\pi_{V}^{\text {old }}\right]$

$\Delta C_{B} \quad$ net decrease of cost for the buyer, in which $\Delta C_{B}=$ $E\left[C_{B}^{\text {old }}\right]-E\left[C_{B}^{\text {new }}\right]$

Assumptions:

(1) the system consists of a single vendor and a single buyer.

(2) demand for the single product is constant over an infinite time horizon.

(3) production rate is uniform and finite.

(4) successive deliveries are scheduled so that shipments arrive at the buyer when its stock from previous shipment has just been used up; that is, the buyer places an order at each cycle and the supplier delivers these items using lot-splitting shipments.

(5) shortages are not allowed.

(6) number of perfect units is at least equal to the demand during the screening time.

(7) the vendor delivers defective items in a single batch at the end of the buyer's $100 \%$ screening process.

\section{THE MATHEMATICAL PROGRAMMING MODEL}

In this section, we first derived the vendor's and the buyer's annual total costs, and then formulated a mathematical programming model for the supply chain system considered. According to Huang's work [17], the ultimate form of JIT purchasing should be adopted to minimize the total cost by implementing frequent deliveries in small lots based on a vendor-buyer long-term agreement. Therefore, the vendor's annual total cost (including setup cost, holding cost, and warranty cost for defective products) is given by

$$
\begin{aligned}
T C_{V}(n, Q)= & \frac{S_{V} D}{n(1-Y) Q}+\frac{v D Y}{(1-Y)} \\
& +\left[\frac{Q}{2}+\frac{(n-2) Q}{2}\left(1-\frac{D}{(1-Y) M}\right)\right] h_{V}
\end{aligned}
$$

Also, the buyer's annual total cost (including ordering cost, holding cost, and transportation and screening cost) is given by

$$
\begin{aligned}
T C_{B}(n, Q)= & \frac{S_{B} D}{n(1-Y) Q}+\frac{F D}{(1-Y) Q}+\frac{d D}{(1-Y)} \\
& +\left[\frac{Q(1-Y)}{2}+\frac{D Q Y}{x(1-Y)}\right] h_{B}
\end{aligned}
$$


In the proposed model, the buyer is allowed to determine its ordering lead time $T$, and the vendor will be beneficial if ordering lead time is long enough for the vendor to make production plan more efficiently. The effect of ordering lead time is reflected in the model by the vendor's unit production cost $C(T)$, which is assumed to decrease as ordering lead time increases. Meanwhile, the vendor is willing to offer price discounts in order to motivate the buyer to provide longer ordering lead time. The pricing policy effect is reflected in the model by the buyer's unit purchasing price $P(T)$, which is assumed to decrease as ordering lead time increases. Although both the vendor and the buyer can be beneficial due to the reduction of production cost and purchasing cost respectively, the vendor's profit may be decreased in the same time because of its pricing policy. Furthermore, when ordering lead time becomes longer, both the vendor and the buyer have to take into consideration of the uncertainty of order cancellation and delivery delay, respectively. In the proposed model, the effect of uncertainty is reflected by the vendor's unit risk cost $R_{V}(T)$ and the buyer's unit risk cost $R_{B}(T)$.

As stated above, the vendor's and the buyer's annual total costs are modified as follows:

$$
\begin{aligned}
T C_{V}(n, Q, T)= & \frac{S_{V} D}{n(1-Y) Q}+\frac{v D Y}{(1-Y)} \\
& +\left[\frac{Q}{2}+\frac{(n-2) Q}{2}\left(1-\frac{D}{(1-Y) M}\right)\right] h_{V} \\
& +C(T) D+r C_{0} R_{V}(T) D
\end{aligned}
$$

$$
\begin{aligned}
T C_{B}(n, Q, T)= & \frac{S_{B} D}{n(1-Y) Q}+\frac{F D}{(1-Y) Q}+\frac{d D}{(1-Y)} \\
& +I P(T)\left[\frac{Q(1-Y)}{2}+\frac{D Q Y}{x(1-Y)}\right] \\
& +P(T) D+z P_{0} R_{B}(T) D
\end{aligned}
$$

in which $P(T) D$ is the buyer's annual purchasing cost (or the annual sales for the vendor) and $C(T) D$ is the vendor's annual production cost. Note that holding $\operatorname{cost} h_{B}$ is replaced by $I P(T)$ to reflect the influence of unit purchasing cost that depends on the vendor's policy

For simplicity, let $T C_{V}=T C_{V}(n, Q, T)$ and $T C_{B}=T C_{B}(n, Q$, $T)$. Therefore, the vender's annual total profit can be expressed as

$$
\pi_{V}=P(T) D-T C_{V}
$$

Since $Y$ is a random variable with a known probability density function $f(y)$, the expected value of (4) and (5) are given by

$$
\begin{aligned}
E\left[\pi_{V}\right]= & P(T) D-\left\{\frac{S_{V} D}{n Q} \frac{1}{E[(1-Y)]}\right. \\
& \left.+v D E\left[\frac{Y}{(1-Y)}\right]+C(T) D+r C_{0} R_{V}(T) D\right\} \\
& -\left\{\left[\frac{Q}{2}+\frac{(n-2) Q}{2}\left(1-\frac{1}{E(1-Y)} \frac{D}{M}\right)\right] h_{V}\right\} \\
& +P(T) D+z C_{B} R_{B}(T) D \\
& \frac{S_{B} D}{n Q} \frac{1}{E[(1-Y)]}+\frac{F D}{Q} \frac{1}{E[(1-Y)]}+d D \frac{1}{E[(1-Y)]} \\
& +I P(T)\left[\frac{Q E[(1-Y)]}{2}+\frac{D Q}{x} E\left[\frac{Y}{1-Y}\right]\right]
\end{aligned}
$$

Now, we are ready to formulate a mathematical programming model for the supply chain system considered. Let $E\left[T C_{B}^{\text {old }}\right]$ and $E\left[\pi_{V}^{\text {old }}\right]$ be the buyer's expected annual total cost and the vendor's expected annual total profit before coordination, respectively; also let $E\left[T C_{B}^{\text {new }}\right]$ and $E\left[\pi_{V}^{\text {new }}\right]$ be the buyer's expected annual total cost and the vendor's expected annual total profit after coordination, respectively. Define $\Delta C_{B}=E\left[T C_{B}^{\text {old }}\right]-E\left[T C_{B}^{\text {new }}\right]$ and $\Delta \pi_{V}=E\left[\pi_{V}^{\text {new }}\right]-E\left[\pi_{V}^{\text {old }}\right]$, in which $\Delta C_{B}$ is the net decrease in cost for the buyer and $\Delta \pi_{V}$ is the net increase in profit for the vendor. The mathematical programming model for the problem considered can then be formulated as follows:

\section{Coordination Model}

Maximize $Z=\Delta \pi_{V}+\Delta C_{B}$

$$
\begin{array}{r}
\text { subject to } \Delta C_{B}=E\left[T C_{B}^{\text {old }}\right]-E\left[T C_{B}^{\text {new }}\right] \geq 0 \\
\Delta \pi_{V}=E\left[\pi_{V}^{\text {new }}\right]-E\left[\pi_{V}^{\text {old }}\right] \geq 0
\end{array}
$$

As shown in the above coordination model, the objective is to maximize the overall supply chain system benefit represented by the sum of the net increase in the vendor's profit $\Delta \pi_{V}$ and the decrease in the buyer's cost $\Delta C_{B}$. The constraints (C1) and $(\mathrm{C} 2)$ are given to ensure that both the vendor and the buyer benefit through coordination, which simply says that the vendor must have a non-negative net increase in profit and the buyer must have a non-negative net decrease in cost. Note that, although all individual costs in this paper are assumed to be EOQ-based well-behaved functions, the resulting model is a 
general nonlinear programming (NLP) problem which is too complicated to solve explicitly (in our experience it is quite difficult even to investigate the behavior of the Hessian matrix for the associated Lagrange function). Instead of using techniques for NLP problems to solve the general complicated model, we solve in the following section the resulting model using specific cost functions, and conduct sensitivity analysis to illustrate the effect of the cost function parameters on supply chain system coordination in the problem considered.

\section{AN ILLUSTRATIVE EXAMPLE AND SENSITIVITY ANALYSIS}

\section{An Illustrative Example}

The derivation for the buyer's expected annual total cost is as follows. As defined above, let $P_{0}$ be the unit purchasing cost with $T=0$ (i.e., without purchasing discount). The buyer's expected annual total cost without purchasing discount, $E\left[T C_{B}^{\text {old }}\right]$, is given by

$$
\begin{aligned}
E\left[T C_{B}^{\text {old }}\right]= & \frac{S_{B} D}{n^{\text {old }} Q^{\text {old }}} \frac{1}{E[(1-Y)]}+\frac{F D}{Q^{\text {old }}} \frac{1}{E[(1-Y)]} \\
& +d D \frac{1}{E[(1-Y)]}+P_{0} D \\
& +I P_{0}\left[\frac{Q^{\text {old }} E[(1-Y)]}{2}+\frac{D Q^{\text {old }}}{x} E\left[\frac{Y}{1-Y}\right]\right]
\end{aligned}
$$

Since the buyer's unit purchasing cost is allowed to depend on the vendor's pricing policy, we assumed that the buyer's unit purchasing cost is given by $P(T)=P_{0} e^{-\beta T}$, which has been utilized by many researches such as Nasri et al. [25], Kim et al. [19], Paknejad et al. [28], Ouyang and Chang [26], and Chang et al. [5]. We also assumed that the buyer's unit risk cost function is given by $R_{B}(T)=\left(e^{T}-1\right) / \beta$. The buyer's expected annual total cost with purchasing discount, $E\left[T C_{B}^{\text {new }}\right]$, is then given by

$$
\begin{aligned}
E\left[T C_{B}^{\text {new }}\right]= & \frac{S_{B} D}{n^{\text {new }} Q^{\text {new }}} \frac{1}{E[(1-Y)]}+\frac{F D}{Q^{\text {new }}} \frac{1}{E[(1-Y)]} \\
& +d D \frac{1}{E[(1-Y)]}+P_{0} e^{-\beta T} D \\
& +I P_{0} e^{-\beta T}\left[\frac{Q^{\text {new }} E[(1-Y)]}{2}+\frac{D Q^{\text {new }}}{x} E\left[\frac{Y}{1-Y}\right]\right] \\
& +\frac{\left(e^{T}-1\right)}{\beta} P_{0} r D
\end{aligned}
$$

Thus, the cost decrease for the buyer, $\Delta C_{B}$, through coordination is simply given by $\Delta C_{B}=E\left[T C_{B}^{\text {old }}\right]-E\left[T C_{B}^{\text {new }}\right]$.

Similarly, the vendor's expected annual total profit is derived as follows. Let $C_{0}$ be the vendor's unit production cost with $T=0$ (i.e., without cost saving). The vendor's expected annual total profit without cost savings, $E\left[\pi_{V}^{\text {old }}\right]$, is then given by

$$
\begin{aligned}
E\left[\pi_{V}^{\text {old }}\right]= & P_{0} D-\left\{\frac{S_{V} D}{n^{\text {old }} Q^{\text {old }}} \frac{1}{E[(1-Y)]}+v D E\left[\frac{Y}{(1-Y)}\right]+C_{0} D\right\} \\
& -\left\{\left[\frac{Q^{\text {old }}}{2}+\frac{(n-2) Q^{\text {old }}}{2}\left(1-\frac{1}{E(1-Y)} \frac{D}{M}\right)\right] h_{V}\right\}
\end{aligned}
$$

Assume that the vendor's unit production cost is given by $C=C_{0}(1-\alpha T)$, and let the vendor's unit risk cost function be $R_{V}(T)=\left(e^{T}-1\right) / \alpha$. The vendor's expected annual total profit with cost savings, $E\left[\pi_{V}^{\text {new }}\right]$, is then given by

$$
\begin{aligned}
E\left[\pi_{V}^{\text {new }}\right]= & P_{0} e^{-\beta T} D-\left\{\frac{S_{V} D}{n^{\text {new }} Q^{\text {new }}} \frac{1}{E[(1-Y)]}\right. \\
& \left.+v D E\left[\frac{Y}{(1-Y)}\right]+C_{0}(1-\alpha T) D\right\} \\
& -\left\{\left[\frac{Q^{\text {new }}}{2}+\frac{(n-2) Q^{\text {new }}}{2}\left(1-\frac{1}{E(1-Y)} \frac{D}{M}\right)\right] h_{V}\right\} \\
& -\frac{e^{T}-1}{\alpha} z C_{0} D
\end{aligned}
$$

Thus, the vendor's profit increase, $\Delta \pi_{V}$, through coordination is given by $\Delta \pi_{V}=E\left[\pi_{V}^{\text {new }}\right]-E\left[\pi_{V}^{\text {old }}\right]$. In the remainder of this section, numerical results from the illustrative example and sensitivity analysis of the cost function parameters are given to show the effectiveness of the proposed model.

\section{Numerical Results}

To illustrate the proposed model, we considered an integrated production-inventory problem with modified data in Huang [17], summarized as follows

- production rate $M=160000$ units/year

- demand rate $D=50000$ units/year

- vendor's setup and holding costs are $S_{V}=\$ 300 /$ cycle and $h_{V}=\$ 2 /$ unit/year

- buyer's ordering and holding cost are $S_{B}=\$ 100 /$ cycle and 
Table 1. Comparison of results by the integration and the coordination models.

\begin{tabular}{|l|c|c|}
\hline & $\begin{array}{c}\text { Integration } \\
\text { model }\end{array}$ & $\begin{array}{c}\text { Coordination } \\
\text { model }\end{array}$ \\
\hline Ordering quantity & 780.268 & 790.48 \\
\hline Number of shipments & 7 & 7 \\
\hline Cost for buyer & $\$ 2530017$ & $\$ 2441354$ \\
\hline Cost for vendor & $\$ 1537065$ & $\$ 1037564$ \\
\hline Total cost & $\$ 4067082$ & $\$ 3478918$ \\
\hline Profit for vendor & $\$ 962935$ & $\$ 1060333$ \\
\hline Cost decrease for buyer & \multicolumn{2}{|c|}{$\$ 88663$} \\
\hline Profit increase for vendor & \multicolumn{2}{|c|}{$\$ 97398$} \\
\hline Total benefit for whole system & \multicolumn{2}{|c|}{2.466061} \\
\hline Ordering lead time & \multicolumn{2}{|c|}{} \\
\hline
\end{tabular}

$h_{B}=\$ 5 /$ unit/year

- holding cost for vendor $h_{V}=\$ 2 / \mathrm{unit} / \mathrm{month}$, holding cost for buyer

- transportation cost $F=\$ 25 /$ delivery

- screening rate $x=1752000$ unit/year

- screening cost $d=\$ 0.5 /$ unit

- warranty cost of imperfect quality items $v=\$ 30 /$ unit

- percentage defective $Y$ is uniformly distributed with probability density function given by $f(y)=25$ for $0 \leq y \leq 0.04$.

Also, parameters used in the coordination model include: $\alpha=0.08, \beta=0.03, r=z=0.0001, P_{0}=\$ 50 /$ unit, and $C_{0}=$ $\$ 30 /$ unit. Computer software LINGO 8.0 is used to solve the resulting coordination model.

Table 1 summarizes the numerical results obtained by Huang's integration model and by our proposed coordination model. As shown in Table 1, both the vendor's and the buyer's total costs obtained by the proposed coordination model are better (i.e., less) than that of Huang's integration model. The vendor's total profit obtained using the proposed coordination model is also better (i.e., greater) than that of Huang's integration model. That is, the numerical results showed that both the vendor and the buyer benefit through coordination, in which the vendor has a profit increase of $\$ 97398$ and the buyer has cost decrease of $\$ 88663$ for buyer. The supply chain system achieves a maximum benefit of $\$ 186061$. These results are consistent with that of Zhao et al. [47].

\section{Sensitivity Analysis of Cost Parameters $\alpha$ and $\beta$}

In the numerical example, we used $C(T)=C_{0}(1-\alpha T)$ and $P(T)=P_{0} e^{-\beta T}$ as the vendor's unit production cost function and the buyer's unit purchasing cost function, respectively. The parameter values $\alpha=0.08$ and $\beta=0.03$ were chosen arbitrarily to illustrate the coordination results. In this subsection we perform sensitivity analysis on parameters $\alpha$ and $\beta$ to investigate their effects on the vendor's net profit increase, the buyer's net cost decrease, and the overall benefit of the supply chain system.
Table 2. The effect of $\alpha$ with $\beta=0.03$.

\begin{tabular}{|c|c|r|c|c|r|r|}
\hline$\alpha$ & $T$ & $Q$ & $n$ & $\begin{array}{c}\text { Buyer's } \\
\text { cost } \\
\text { decrease }\end{array}$ & $\begin{array}{c}\text { Vendor's } \\
\text { profit } \\
\text { increase }\end{array}$ & $\begin{array}{c}\text { System's } \\
\text { overall } \\
\text { benefit }\end{array}$ \\
\hline 0.050 & 0.520 & 5744.7 & 1 & 22381 & 0 & 22381 \\
\hline 0.060 & 2.118 & 789.1 & 7 & 93082 & 18418 & 111500 \\
\hline 0.070 & 2.305 & 789.8 & 7 & 91964 & 55652 & 147616 \\
\hline 0.080 & 2.465 & 790.5 & 7 & 88664 & 97398 & 186062 \\
\hline 0.090 & 2.603 & 791.0 & 7 & 83746 & 142744 & 226510 \\
\hline 0.100 & 2.725 & 791.5 & 7 & 77590 & 191124 & 268714 \\
\hline
\end{tabular}

In the first part of the sensitivity analysis, we investigated the effect of parameter $\alpha$ while $\beta=0.03$ remains unchanged. Recall that the vendor's unit production cost function is assumed to be $C(T)=C_{0}(1-\alpha T)$, that is, the vendor's unit production cost decreases as $\alpha$ increases. However, in the real world $\alpha$ cannot be reduced without bound due to the fixed cost and other variable costs. As can be expected, the overall benefit of the supply chain system will be better off if $\alpha$ increases and this is shown in the results in Table 2. In the table, we see that ordering lead time elongates as $\alpha$ increases. The overall benefit of the supply chain system increases from $\$ 22,381$ to $\$ 268,714$ when $\alpha$ increases from 0.050 to 0.100 . Also shown in the table, we see that both the vendor and the buyer benefit through coordination. There are two notable interesting results: First, as seen in the first row of Table 2 in which $\alpha=0.050$ and $\beta=0.003$, only one side (i.e., the buyer) gets the benefit. The associated solution is given by $Q=$ 5744.7 and $N=1$. This result agrees with the conclusions in Huang [17]. In this situation, coordination may be broken at any time because the vender does not share the benefit. Second, as shown in the table, if the total number of shipments per lot from the vendor to the buyer are the same, the size of each shipment increases as $\alpha$ increases.

The second part of sensitivity analysis is the investigation of the parameter $\beta$ effect while $\alpha=0.08$ remains unchanged. Recall that the buyer's unit purchasing cost function is assumed to be $P(T)=P_{0} e^{-\beta T}$, in which the buyer's unit purchasing cost decreases as $\beta$ increases. Similar results are obtained as shown in Table 3 . In the table we see that the overall supply chain system benefit increases from $\$ 149,096$ to $\$ 211,430$ when $\beta$ increases from 0.020 to 0.04 , which shows that both parties benefit because of coordination. However, as $\beta$ increases to 0.050 , only one side (i.e., the buyer) gets the benefit. The reason is that the vendor's cost savings (due to the shorter ordering lead time by the buyer) are transferred to the buyer. The associated solution is given by $Q=5968.9$ and $N=1$. In this situation, coordination may be broken at any time because the vender does not share the benefit. Note that as $\beta$ increases, the total number of shipments per lot from the vendor to the buyer decreases and the size of each shipment from the vendor to the buyer increases. 
Table 3. The effect of $\beta$ during $\alpha=0.08$.

\begin{tabular}{|c|c|r|c|c|c|c|}
\hline$\beta$ & $T$ & $Q$ & $n$ & $\begin{array}{c}\text { Buyer's } \\
\text { cost } \\
\text { decrease }\end{array}$ & $\begin{array}{c}\text { Vendor's } \\
\text { profit } \\
\text { increase }\end{array}$ & $\begin{array}{c}\text { System's } \\
\text { overall } \\
\text { benefit }\end{array}$ \\
\hline 0.020 & 2.120 & 786.2 & 7 & 12100 & 136995 & 149096 \\
\hline 0.030 & 2.465 & 790.5 & 7 & 88663 & 97398 & 186062 \\
\hline 0.040 & 2.693 & 795.0 & 7 & 169415 & 42015 & 211430 \\
\hline 0.050 & 0.282 & 5968.9 & 1 & 22184 & 0 & 22184 \\
\hline
\end{tabular}

Table 4. The simultaneous effect of $\alpha$ and $\beta$.

\begin{tabular}{|c|c|c|c|c|r|r|c|}
\hline$\alpha$ & $\beta$ & $T$ & $Q$ & $n$ & $\begin{array}{c}\text { Buyer's } \\
\text { cost } \\
\text { decrease }\end{array}$ & $\begin{array}{c}\text { Vendor's } \\
\text { profit } \\
\text { increase }\end{array}$ & $\begin{array}{c}\text { System's } \\
\text { overall } \\
\text { benefit }\end{array}$ \\
\hline 0.07 & 0.02 & 1.970 & 785.8 & 7 & 19515 & 97054 & 116569 \\
\hline 0.07 & 0.04 & 2.527 & 794.1 & 7 & 168577 & 294 & 168871 \\
\hline 0.08 & 0.03 & 2.465 & 790.5 & 7 & 88663 & 97399 & 186062 \\
\hline 0.09 & 0.04 & 2.837 & 795.8 & 7 & 168018 & 88009 & 256027 \\
\hline 0.09 & 0.02 & 2.255 & 786.5 & 7 & 3670 & 179924 & 183594 \\
\hline
\end{tabular}

In the third part of the sensitivity analysis, we investigated the effect of changing parameters $\alpha$ and $\beta$ simultaneously. Since both the vendor's unit production cost and the buyer's unit purchasing cost decrease as $\alpha$ and $\beta$ increases, similar results are expected in that the overall system benefit will increase when $\alpha$ and $\beta$ increase. As shown in Table 4, we see that both parties benefit through coordination. In the table we use the case of $\alpha=0.08$ and $\beta=0.03$ (shown in the fourth row of the table) as comparison basis, and we observe two interesting results:

(i) As seen in the second row (the case of $\alpha=0.07$ and $\beta=$ 0.02 ) and the fifth row (the case of $\alpha=0.09$ and $\beta=0.04$ ) of the table, the systems' overall benefit decreases (or increases) when $\alpha$ and $\beta$ increase (or decreases) simultaneously. In these cases, the benefits to both the vendor and the buyer are reduced;

(ii) As shown in the third row (the case of $\alpha=0.07$ and $\beta=$ 0.04 ) and the sixth row (the case of $\alpha=0.09$ and $\beta=0.02$ ) of the table, the system's overall benefit decreases in both cases. That is, either when $\alpha$ increases and $\beta$ decreases simultaneously or when $\alpha$ decreases and $\beta$ increases simultaneously, the system's overall benefit decreases.

\section{Sensitivity Analysis of Defective Rate}

In the last part of the sensitivity analysis, we explored the effect of the defect rate on the optimal solution. Suppose that the percentage defective random variable $Y$ is uniformly distributed with probability density function given by

$$
f(y)=\left\{\begin{array}{l}
1 / U, \quad 0 \leq y \leq U \\
0, \quad \text { otherwise }
\end{array}\right.
$$

Table 5. The effect of $Y$ with $\alpha=0.08$ and $\beta=0.03$.

\begin{tabular}{|c|c|c|c|c|c|c|}
\hline$U$ & $T$ & $Q$ & $n$ & $\begin{array}{c}\text { Buyer's } \\
\text { cost } \\
\text { decrease }\end{array}$ & $\begin{array}{c}\text { Vendor's } \\
\text { profit } \\
\text { increase }\end{array}$ & $\begin{array}{c}\text { System's } \\
\text { overall } \\
\text { benefit }\end{array}$ \\
\hline 0.01 & 2.464739 & 782.2 & 7 & 88657 & 97405 & 186062 \\
\hline 0.02 & 2.464740 & 784.9 & 7 & 88659 & 97403 & 186062 \\
\hline 0.04 & 2.464741 & 790.5 & 7 & 88663 & 97399 & 186062 \\
\hline 0.08 & 2.464745 & 802.0 & 7 & 88674 & 97390 & 186064 \\
\hline 0.16 & 2.464752 & 826.7 & 7 & 88700 & 97376 & 186076 \\
\hline
\end{tabular}

To evaluate the defect rate effect on $n^{*}, Q^{*}$, and $T^{*}$, we examined different values of $U(0.01 \leq U \leq 0.16)$. Table 5 shows the behaviors of the optimal solutions versus different $U$. From the results, we can see that when $U$ increases, the values of $T$ and $Q$ increase; while $n$ holds constant. Furthermore, as $U$ increases, buyer's reduction in cost increases; while vendor's increment in profit decreases. Thus, when the defective rate increases, the vendor needs to deliver greater lot size per shipment to satisfy the buyer demand. As the defect rate increases, the system's benefit increases simultaneously. This result indicates the greater the number of defects, the greater the importance of coordination for the vendor and buyer. Obviously, the defect rate has low sensitivity to the system's overall benefit and for the ordering lead time.

\section{CONCLUSION}

This paper considered the issue of coordination for a simple single-vendor, single-buyer supply chain system, in which the buyer's ordering lead time is affected by purchasing price discounts which in turn are affected by the vendor's pricing policy. For practical purposes, risk costs and imperfect product quality were also included. We proposed a mathematical programming model, called the coordination model, in which the objective is to maximize the overall system benefit and also guarantee that both parties benefit financially. From the sensitivity analysis results for the illustrative numerical example, based on the assumed but realistic cost functions, we see that the maximum supply chain system benefit can be achieved through coordination and both parties of the supply chain system are beneficial. Future research includes an investigation into the effect of different cost functions, more realistic and complicated inventory models to show that coordination is indeed a win-win policy for conflicting parties in the supply chain system. The overall system benefits and the individual parties in the supply chain system can achieve further improved benefit through coordination.

\section{ACKNOWLEDGMENTS}

The authors are grateful to the anonymous referees for their very valuable and helpful suggestions on an earlier version of the paper. 


\section{REFERENCES}

1. Bakal, I. S., Geunes, J., and Romeijn, H. E., "Market selection decisions for inventory models with price-sensitive demand," Journal of Global Optimization, Vol. 41, pp. 633-657 (2008).

2. Banerjee, A., "A joint economic-lot-size model for purchaser and vendor," Decision Science, Vol. 17, pp. 292-311 (1986).

3. Ben-Daya, M., Darwish, M., and Ertogral, K., "The joint economic lot sizing problem: Review and extensions," European Journal of Operational Research, Vol. 185, pp. 726-742 (2008).

4. Ben-Daya, M. and Raouf, A., "Inventory models involving lead time as a decision variable," The Journal of the Operational Research Society, Vol. 45, No. 5, pp. 579-602 (1994).

5. Chang, H. C., Ouyang, L. Y., Wu, K. S., and Ho, C. H., "Integrated vendorbuyer cooperative inventory models with controllable lead time and ordering cost reduction," European Journal of Operational Research, Vol. 170, pp. 481-495 (2006).

6. Chen, L. H. and Kang, F. S., "Coordination between vendor and buyer consider credit and items of imperfect quality," International Journal of Production Economics, Vol. 123, pp. 52-61 (2010).

7. Chung, C. J. and Wee, H. M., "Optimizing the economic lot size of a three-stage supply chain with backordering derived without derivatives," European Journal of Operational Research, Vol. 183, pp. 933-943 (2007).

8. Ertogral, K., Darwish, M., and Ben-Daya, M., "Production and shipment lot sizing in a vendor-buyer supply chain with transportation cost," European Journal of Operational Research, Vol. 176, pp. 1592-1606 (2007).

9. Gerchak, Y., "Order point/order quantity models with random yield," International Journal of Production Economics, Vol. 26, pp. 297-298 (1992).

10. Goyal, S. K., "On improving the single-vendor single-buyer integrated production inventory model with a generalized policy," European Journal of Operational Research, Vol. 125, pp. 429-430 (1976).

11. Goyal, S. K., "A joint economic-lot-size model for purchaser and vendor," Decision Sciences, Vol. 19, pp. 236-241 (1988).

12. Goyal, S. K., “A one-vendor multi-buyer integrated inventory model: A comment," European Journal of Operational Research, Vol. 82, pp. 209210 (1995).

13. Goyal, S. K. and Cardenas-Barron, L. E., "Note on: Economic production quantity model for items with imperfect quality-a practical approach," International Journal of Production Economics, Vol. 77, pp. $85-87$ (2002).

14. Hill, R. M., "The single-vendor single-buyer integrated productioninventory model with a generalized policy," European Journal of Operational Research, Vol. 97, pp. 493-499 (1997).

15. Hill, R. M., "The optimal production and shipment policy for the single-vendor single-buyer integrated production-inventory problem," International Journal of Production Research, Vol. 37, pp. 2463-2475 (1999)

16. Hoque, M. and Goyal, S. K., "A heuristic solution procedure for an integrated inventory system under controllable lead time with equal or unequal sized batch shipments between a vendor and a buyer," International Journal of Production Economics, Vol. 102, pp. 217-225 (2006).

17. Huang, C. K., “An optimal policy for a single-vendor single buyer integrated production-inventory problem with process unreliability consideration," International Journal of Production Economics, Vol. 91, pp. 91-98 (2004)

18. Khouja, M., "The single-period (news-vendor) problem: literature review and suggestions for future research," Omega, Vol. 27, pp. 537-553 (1999).

19. Kim, K. L., Hayya, J. C., and Hong, J. D., "Setup reduction in economic production quantity model," Decision Sciences, Vol. 23, pp. 500-508 (1992).

20. Landeros, R. and Lyth, D. M., "Economic-lot-size models for cooperative inter-organization,” Journal of Business Logistics, Vol. 10, No. 2, 146-158 (1989).

21. Lau, A. H. L. and Lau, H. S.. "The effects of reducing demand uncertainty in a manufacturer - retailer channel for single-period products," Computers \& Operations Research, 29: 1583-602 (2002).
22. Liao, C. J. and Shyu, C. H., "An analytical determination of lead time with normal demand," International Journal of Operations \& Production Management, Vol. 11, No. 9, pp. 72-78 (1991).

23. Maddah, B. and Jaber, M. Y., "Economic order quantity for items with imperfect quality: Revisited," International Journal of Production Economics, Vol. 112, pp. 808-815 (2008).

24. Mantrala, M. K. and Raman, K., 'Demand uncertainty and supplier's returns policies for a multi-store style-good retailer," European Journal of Operational Research, Vol. 115, pp. 270-284 (1999).

25. Nasri, F., Affisco, J. F., and Paknejad, M. T., "Setup cost reduction in an inventory model with finite range stochastic lead times," International Journal of Production Research, Vol. 28, pp. 199-212 (1990).

26. Ouyang, L. Y. and Chang, H. C., "A minimax distribution free procedure for mixed inventory models involving variable lead time with fuzzy lost sales," International Journal of Production Economics, Vol. 76, pp. 1-12 (2002).

27. Ouyang, L. Y., Wu, K. S., and Ho, C. H., "The single-vendor single-buyer integrated inventory problem with quality improvement and lead time reduction - MinMax distribution free approach," Asia-Pacific Journal of Operational Research, Vol. 23, No. 3, 407-424 (2006).

28. Paknejad, M. J., Nasri, F., and Affisco, J. F., "Defect units in a continuous review (s,Q) system," International Journal of Production Research, Vol. 33, pp. 2767-2777 (1995).

29. Pan, J. C. and Yang, J. S., "A study of an integrated inventory with controllable lead time," International Journal of Production Research, Vol. 40, pp. 1263-1273 (2002).

30. Pan, K., Lai, K. K., Liang, L., and Leung, S. C. H., "Two-period pricing and ordering policy for the dominant retailer in a two-echelon supply chain with demand uncertainty," Omega, Vol. 37, pp. 919-929 (2009).

31. Papachristos, S. and Konstantaras, I., "Economic ordering quantity models for items with imperfect quality," International Journal of Production Economics, Vol. 100, pp. 148-154 (2006).

32. Parlar, M. and Weng, Z. K., "Designing a firm's coordinated manufacturing and supply decisions with short product life cycles," Management Science, Vol. 43, No. 10, pp. 1329-1344 (1997).

33. Petruzzi, N. C. and Dada, M., "Pricing and the newsvendor problem: A review with extensions," Operations Research, Vol. 47, pp. 183-194 (1999).

34. Porteus, E. L., "Optimal lot sizing, process quality improvement and setup cost reduction," Operations Research, Vol. 34, No. 1, pp. 137-144 (1986).

35. Qin, Y., Tang, H., and Guo, C., "Channel coordination and volume discounts with price-sensitive demand," International Journal of Production Economics, Vol. 105, pp. 43-53 (2007).

36. Rau, H. and OuYang, B. C., "An optimal batch size for integrated production - inventory policy in a supply chain," European Journal of Operational Research, Vol. 185, pp. 619-634 (2008).

37. Ray, S., Gerchak, Y., and Jewkes, E. M., "Joint pricing and inventory policies for make-to-stock products with deterministic price-sensitive demand," International Journal of Production Economics, Vol. 97, pp. 143-158 (2005).

38. Rosenblatt, M. J. and Lee, H. L., "Economic production cycles with imperfect production processes," IIE Transactions, Vol. 18, No. 1, pp. 48-55 (1986).

39. Sajadieh, M. S., and Akbari Jokar, M. R., "Optimizing shipment, ordering and pricing policies in a two-stage supply chain with price-sensitive demand," Transportation Research Part E, doi:10.1016/j.tre.2008.12.02 (2009).

40. Salameh, M. K. and Jaber, M. Y., "Economic production quantity model for items with imperfect quality," International Journal of Production Economics, Vol. 64, pp. 59-64 (2000).

41. Sarmah, S. P., Scharya, D., and Goyal, S. K., "Buyer-vendor coordination models in supply chain management," European Journal of Operational Research, Vol. 175, pp. 1-15 (2006).

42. Schwaller, R. L., "EOQ under inspection costs," Production and Inventory Management, Vol. 29, No. 3, pp. 22-24 (1988). 
43. Viswanathan, S., "Optimal strategy for the integrated vendor-buyer inventory model," European Journal of Operational Research, Vol. 105, pp. 38-42 (1998).

44. Viswanathan, S. and Wang, Q., "Discount pricing decisions in distribution channels with price-sensitive demand," European Journal of Operational Research, Vol. 149, pp. 571-587 (2003).

45. Wee, H. M., Yu, F., and Chen, M. C., "Optimal inventory model for items with imperfect quality and shortage backordering," Omega, Vol. 35, pp.
7-11 (2007).

46. Weng, Z. K., "Pricing and ordering strategies in manufacturing and distribution alliances," IIE Transactions, Vol. 29, No. 8, pp. 681-692 (1997).

47. Zhao, X., Xie, J., and Wei, J. C., "The value of early order commitment in a two-level supply chain," European Journal of Operational Research, Vol. 180, pp. 194-214 (2007). 